\title{
Biometria e trocas gasosas de palmeiras ornamentais em diferentes fontes de adubação
}

\author{
Biometrics and gas exchange of ornamental palm trees in different sources of fertilization \\ Biometría e intercambio de gases de palmeras ornamentales en diferentes fuentes de fertilización
}

Recebido: 17/03/2021 | Revisado: 23/03/2021 | Aceito: 27/03/2021 | Publicado: 04/04/2021

Eloyza Marye Leão Cardoso

ORCID: https://orcid.org/0000-0002-2938-9895

Universidade Federal Rural da Amazônia, Brasil

E-mail: eloyzacardoso2@gmail.com

Camila Gurjão Da Costa

ORCID: https://orcid.org/0000-0002-8658-2149

Universidade Federal Rural da Amazônia, Brasil

E-mail: gurj.mila@gmail.com

Luiz Augusto Silva de Sousa

ORCID: https://orcid.org/0000-0001-6454-7556

Universidade Federal Rural da Amazônia, Brasil

E-mail: luiz.augusto@ufra.edu.br

Erick dos Santos Ribeiro

ORCID: https://orcid.org/0000-0002-9204-366X

Universidade Federal Rural da Amazônia, Brasil

E-mail: erick.rib39@gmail.com

Juciane Martins de Sousa

ORCID: https://orcid.org/0000-0002-4063-7394

Universidade Federal Rural da Amazônia, Brasil

E-mail: juciane.ufra@gmail.com

Francimary da Silva Carneiro

ORCID: https://orcid.org/0000-0002-1693-8779

Universidade Federal Rural da Amazônia, Brasil

E-mail: francimarycarneiro@gmail.com

Aline Cecy Rocha de Lima

ORCID: https://orcid.org/0000-0001-5887-3689

Universidade Federal do Pará, Brasil

E-mail: alinececy@yahoo.com

Marcio Braga Amorim

ORCID: https://orcid.org/0000-0001-7508-2766

Secretaria de Estado de Meio Ambiente e Sustentabilidade, Brasil

E-mail: marciobamorim@gmail.com

\begin{abstract}
Resumo
Objetivando analisar as características biométricas e padrões de trocas gasosas no desenvolvimento de Veitchia merrillii (Becc.), H. E. Moore, sob efeito de diferentes fontes de adubação, foi conduzido um experimento em ambiente controlado, usando blocos ao acaso como delineamento experimental, composto de 13 tratamentos, com diferentes doses de NPK, de biofertilizante comercial e de biofertilizante caseiro. Mediu-se a altura, o diâmetro do caule e o número de folhas aos 30, 60, 90 e 120 dias após o transplantio (DAT), e fez-se uma análise de trocas gasosas aos 30 DAT. Foi feita análise de regressão para determinar as doses resposta de cada adubo. A dose recomendada para o adubo químico é de $10,5 \mathrm{~g}$, de biofertilizante comercial $150 \mathrm{ml}$. L -1, a dose ideal de biofertilizante caseiro foi linear. Os tratamentos, com exceção da testemunha, apresentaram valores altos de fotossíntese e baixos para transpiração, indicando ótimas condições para campo. $\mathrm{O}$ tratamento que obteve maior êxito quanto às características estéticas foi o tratamento T7.
\end{abstract}

Palavras-chave: Paisagismo; Adubação química; Adubação orgânica; Arecaceae; Veitchia Merrillii.

\begin{abstract}
Aiming to analyze the biometric characteristics and gas exchange patterns in the development of Veitchia merrillii (Becc.), HE Moore, under the effect of different fertilizer sources, an experiment was conducted in a controlled environment, using randomized blocks as an experimental design, composed of 13 treatments, with different doses of NPK, commercial biofertilizer and homemade biofertilizer. Height, stem diameter and number of leaves were measured at 30, 60, 90 and 120 days after transplanting (DAT), and gas exchange analysis was performed at 30 DAT. Regression analysis was performed to determine the response doses of each fertilizer. The recommended dose for the
\end{abstract}


chemical fertilizer is $10.5 \mathrm{~g}$, of commercial biofertilizer $150 \mathrm{ml}$. L -1, the ideal dose of homemade biofertilizer was linear. The treatments, with the exception of the control, showed high values of photosynthesis and low values for transpiration, indicating excellent conditions for the field. The treatment that was most successful in terms of aesthetic characteristics was the $\mathrm{T} 7$ treatment.

Keywords: Landscaping; Chemical fertilization; Organic fertilization; Arecaceae; Veitchia Merrillii.

\section{Resumen}

Con el objetivo de analizar las características biométricas y patrones de intercambio de gases en el desarrollo de Veitchia merrillii (Becc.), HE Moore, bajo el efecto de diferentes fuentes de fertilizantes, se realizó un experimento en un ambiente controlado, utilizando bloques al azar como diseño experimental, compuesto de 13 tratamientos, con diferentes dosis de NPK, biofertilizante comercial y biofertilizante casero. La altura, el diámetro del tallo y el número de hojas se midieron a los 30, 60, 90 y 120 días después del trasplante (DAT), y el análisis de intercambio gaseoso se realizó a los 30 DAT. Se realizó un análisis de regresión para determinar las dosis de respuesta de cada fertilizante. La dosis recomendada para el abono químico es de $10,5 \mathrm{~g}$, de biofertilizante comercial $150 \mathrm{ml}$. L -1, la dosis ideal de biofertilizante casero fue lineal. Los tratamientos, con excepción del testigo, mostraron valores altos de fotosíntesis y bajos valores de transpiración, lo que indica excelentes condiciones para el campo. El tratamiento que tuvo más éxito en cuanto a características estéticas fue el tratamiento T7.

Palabras clave: Paisajismo; Fertilización química; Fertilización orgánica; Arecaceae; Veitchia Merrillii.

\section{Introdução}

Em virtude da vida moderna, o homem tende a se afastar do ambiente natural, surgindo uma necessidade maior de levar plantas para o convívio nos lares, nos jardins, praças e demais áreas de lazer, visando maior conectividade com a natureza. Esse fator promove uma demanda crescente do mercado de plantas ornamentais, tornando esse ramo do agronegócio atrativo e com grande potencial econômico. De acordo com Rentes (1986), O Brasil chegou a ser denominado originalmente "Pindorama" (terra de muitas palmeiras, em tupi), com cerca de 480 espécies de Palmae, cultivadas para fins paisagísticos.

Segundo Fernandes (2015) atualmente, o mercado de plantas ornamentais movimenta cerca de $\mathrm{R} \$ 5,7$ bilhões, onde 8 mil propriedades estão envolvidas nesta atividade, sendo a maioria pequenos proprietários. Afirmando-se que o cultivo de plantas ornamentais é uma atividade consolidada em diversos estados brasileiros, tendo grande importância econômica e social.

As palmeiras, pertencentes à família Arecaceae, possuem um grande potencial ornamental e estão entre as plantas mais utilizadas no paisagismo brasileiro, sendo necessária uma grande demanda de mudas de palmeiras, nativas e exóticas, para esse fim.

O consumidor exige, além de bons preços, qualidade, beleza e durabilidade. Neste sentido, para conseguir plantas com tais características, deve-se lançar mão de tecnologias e processos de manejo adequados de produção, dentre estes a escolha correta do substrato, adubação, formas de aplicação e dosagens, são fundamentais e determinantes para uma produção eficiente e o sucesso do empreendimento.

Um aspecto relevante na implantação de uma espécie ornamental é a etapa de formação, onde as mudas devem ser sadias e ter bom desenvolvimento. Conforme Barbosa et al. (2003), a fase de viveiro constitui-se em uma etapa crucial do cultivo de uma cultura, possibilitando aos agricultores a obtenção de plantas com maior tolerância ás condições adversas de campo.

De acordo com Junqueira (2008), o cultivo de flores e plantas ornamentais contemporâneas possui semelhanças tecnológicas e comerciais com a olericultura, especialmente quanto à utilização do cultivo protegido, substratos e condicionalidades de solo, fertirrigação, entre outros aspectos.

Tem-se que a assimilação de nutrientes, que é o processo pelo qual os nutrientes obtidos pelas plantas, na forma de compostos inorgânicos estáveis de baixa energia, são incorporados em compostos de carbono de alta energia, que são necessários para o crescimento e desenvolvimento dos vegetais. Vale ressaltar que cerca de $90 \%$ da biomassa seca acumulada por um vegetal, ao longo do seu crescimento são resultado da fotossíntese, e $10 \%$ devido a absorção de nutrientes minerais 
(Benincasa, 2003).

A adubação e a nutrição em floricultura tornaram-se complexas, devido à diversidade do meio de cultivo, que pode ser o solo, solo e substrato, substrato ou hidropônico, em sistemas abertos, semi-abertos ou fechados. As formas de aplicação dos fertilizantes via solo, foliar ou fertirrigação, e os tipos de fertilizantes, minerais, orgânicos e de alta solubilidade, vêm sendo realizados e aplicados de uma maneira empírica, muitas vezes, baseados em testes conduzidos pelos próprios agricultores. Embora a informação de agricultores seja um parâmetro importante e, muitas vezes, o único existente em uma atividade recente, torna-se muito pouco para uma atividade profissional, com grandes oportunidades de desenvolvimento, como a floricultura (Furlani\& Castro, 2001).

Devido à pouca disponibilidade de informações cientificas a respeito do cultivo de palmeiras, surge a necessidade de desenvolver estudos sobre a formação de mudas, técnicas de cultivo e fertilização, para através do comportamento dessa espécie em reação aos tratos culturais, definir a melhor forma de manejo para a obtenção de mudas com qualidade estética para os fins paisagísticos. Por isso que neste trabalho objetivou-se analisar características biométricas e parâmetros de trocas gasosas no desenvolvimento de mudas de Veitchia merrillii (Becc.), H. E. Moore, sob efeito de diferentes fontes de adubação, química e orgânica, em diferentes doses.

\section{Metodologia}

\section{Caracterização da área experimental}

O experimento foi realizado em casa de vegetação do MIPDAM (Manejo Integrado de Plantas Daninhas da Amazônia), localizado no Instituto de Ciências Agrárias (ICA) da Universidade Federal Rural da Amazônia (UFRA), campus - Belém, Latitude - $01^{\circ} 45^{\prime}$ 55,36”' S de Longitude -48 43' 85,06”' O, no Município de Belém, Pará, Brasil, no período de outubro de 2018 a janeiro de 2019.

Segundo a classificação climática proposta por Köppen a área é classificada como clima Af (Peel et al., 2007), caracterizado como área de clima tropical, com média da precipitação pluviométrica de $2537 \mathrm{~mm} /$ ano e a temperatura média é de $26.8{ }^{\circ} \mathrm{C}$. Os espécimes vegetais foram desenvolvidos em ambiente seminatural de viveiro, exposto em clima quente e úmido.

\section{Preparo do substrato e mudas}

As mudas com idade de 5 meses foram adquiridas através do viveiro de floricultura e paisagismo localizado no ICAUFRA, cujas sementes foram obtidas na cidade de Marituba, na região metropolitana de Belém. Procedeu-se a seleção dos espécimes que apresentavam características próximas de altura e número de folhas, que aparentavam estar sadias, visando maior uniformidade amostral. O passo seguinte foi a elaboração do substrato, único para todos os tratamentos, composto de terra preta comum e sem aquisição de nenhum produto.

As plantas foram individualmente transplantadas para vasos de polietileno de coloração preto e flexível com capacidade para 3 litros (Figura 1), os quais foram vedados com fita adesiva e sacos plástico preto de polietileno, para evitar a perda de água e nutrientes por lixiviação durante a irrigação, posteriormente as mudas foram transferidas para o local do experimento. Procedeu-se com a adubação após 3 dias, sendo medidos diâmetro, número de folhas e altura de cada indivíduo ao final do transplantio. 
Figura 1 - Preparo dos recipientes (A) e transplantio das mudas (B e C) de Veitchia merrillii.

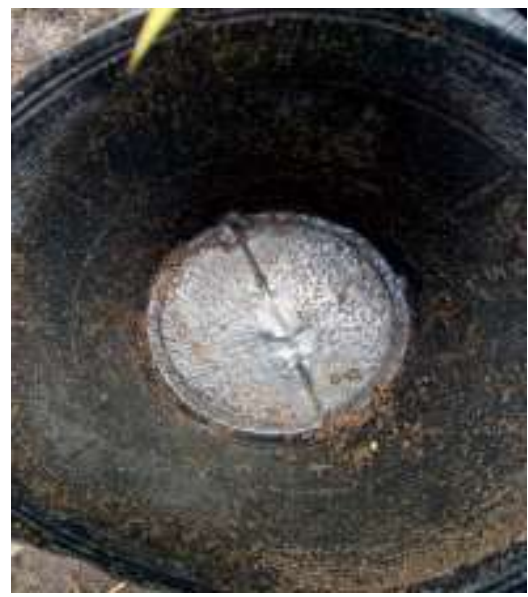

A

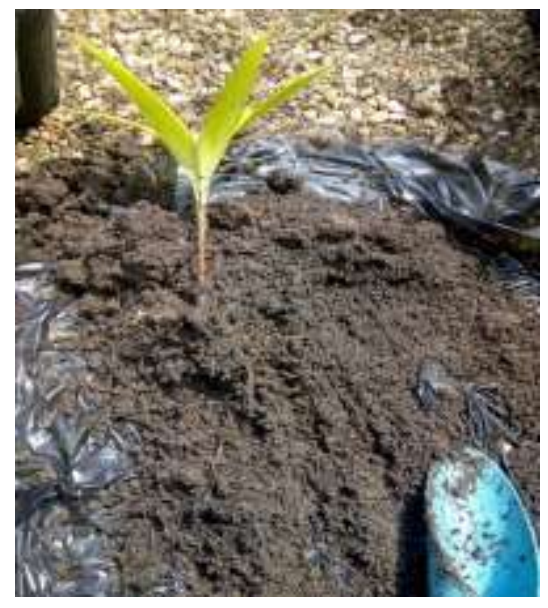

B

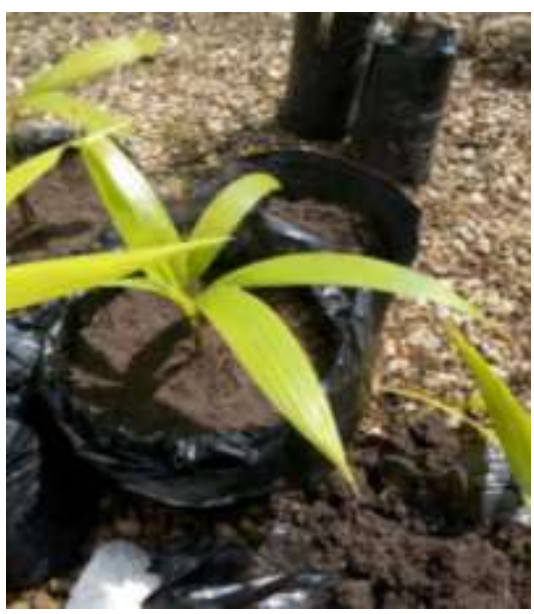

C

Fonte: Autores (2018)

\section{Implantação do experimento e delineamento experimental}

$\mathrm{O}$ delineamento experimental utilizado foi blocos ao acaso, composto por 13 tratamentos, onde $\mathrm{T}_{0}$ corresponde à testemunha (sem adubação); $\mathrm{T}_{1}, \mathrm{~T}_{2}, \mathrm{~T}_{3}$ e $\mathrm{T}_{4}$ à adubação química; $\mathrm{T}_{5}, \mathrm{~T}_{6}, \mathrm{~T}_{7}$, e $\mathrm{T}_{8}$ à adubação de biofertilizante comercial; e $\mathrm{T}_{9}$, $\mathrm{T}_{10}, \mathrm{~T}_{11}$ e $\mathrm{T}_{12}$ à adubação de biofertilizante caseiro. Cada tratamento conteve 4 repetições, sendo nestas cada muda uma unidade amostral, contendo um total de 52 amostras. As avaliações de altura, diâmetro, número de folhas foram realizadas a cada 30 dias (Figura 2).

Figura 2 - Avalições de Altura(A), diâmetro (B) e contagem de folhas (C) de mudas da palmeira V. merrillii.

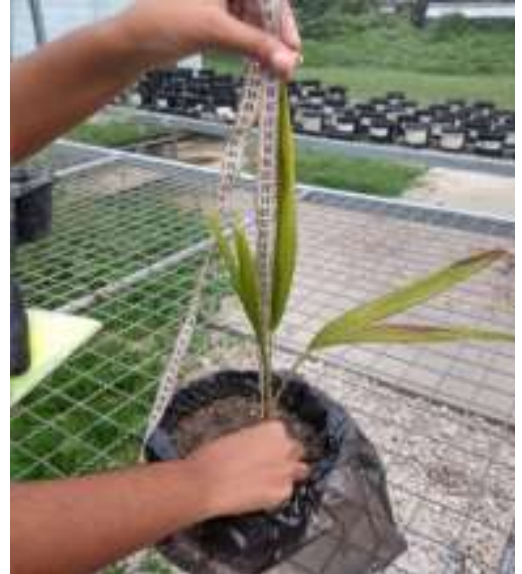

A

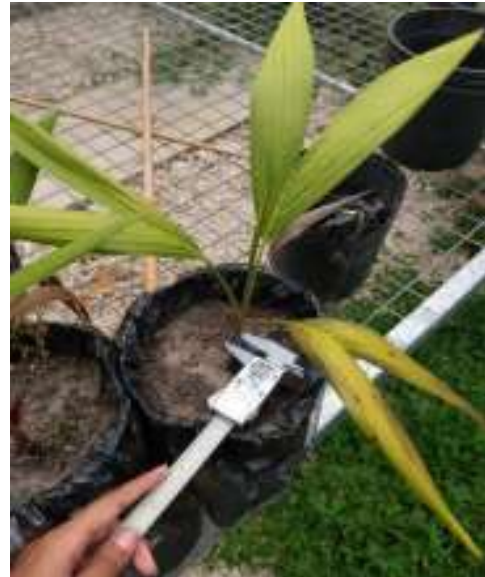

B

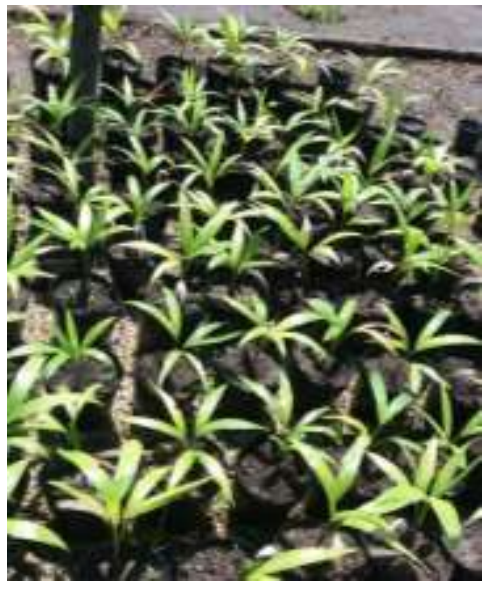

C

Fonte: Autores (2018).

A análise de trocas gasosas ocorreu no $30^{\circ}$ DAT (dia após transplantio). As análises de área foliar, massa seca dos caules, das raízes e das folhas foram obtidas ao final do experimento.

\section{Adubação}

Os tratamentos foram compostos por diferentes dosagens de adubação química (Q) de NPK 10-10-10 nas doses 3,5 g $\left(\mathrm{T}_{1}\right), 7,0 \mathrm{~g}\left(\mathrm{~T}_{2}\right), 10,5 \mathrm{~g}\left(\mathrm{~T}_{3}\right), 14 \mathrm{~g}\left(\mathrm{~T}_{4}\right)$; adubação com fertilizante comercial FORTH palmeiras $(\mathrm{FC})$ nas concentrações $5 \mathrm{ml} / \mathrm{L}$ 
( $\left.\mathrm{T}_{5}\right), 10 \mathrm{ml} / \mathrm{L}\left(\mathrm{T}_{6}\right), 15 \mathrm{ml} / \mathrm{L}\left(\mathrm{T}_{7}\right), 20 \mathrm{ml} / \mathrm{L}\left(\mathrm{T}_{8}\right)$, dissolvidos em água; e adubação com biofertilizante caseiro orgânico (BC) nas concentrações $50 \mathrm{ml} / \mathrm{L}\left(\mathrm{T}_{9}\right), 100 \mathrm{ml} / \mathrm{L}\left(\mathrm{T}_{10}\right), 150 \mathrm{ml} / \mathrm{L}\left(\mathrm{T}_{11}\right), 200 \mathrm{ml} / \mathrm{L}\left(\mathrm{T}_{12}\right)$, dissolvidos em água.

No preparo das dosagens dos biofertilizantes comercial e caseiro, utilizou-se o volume de $100 \mathrm{ml}$ de solução (biofertilizante + água), com auxílio de uma seringa descartável estéril transparente de polipropileno com capacidade para 10 $\mathrm{ml}$ para aferir o volume de biofertilizante concentrado, desta forma a concentração de adubo foi inserida na seringa, em seguida adicionada em um erlenmeyer e por fim completado com água, encanada, inodora, incolor e insípida, até atingir o volume de $100 \mathrm{ml}$ (Figura 3).

Figura 3 - Mensuração das doses de NPK (A), biofertilizante comercial (B) e biofertilizante caseiro (C).

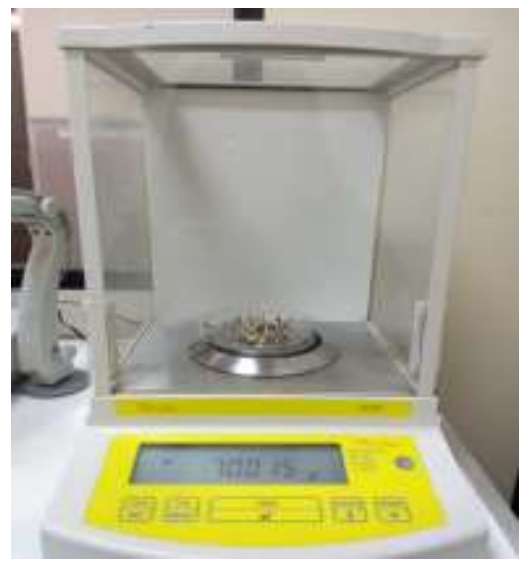

A

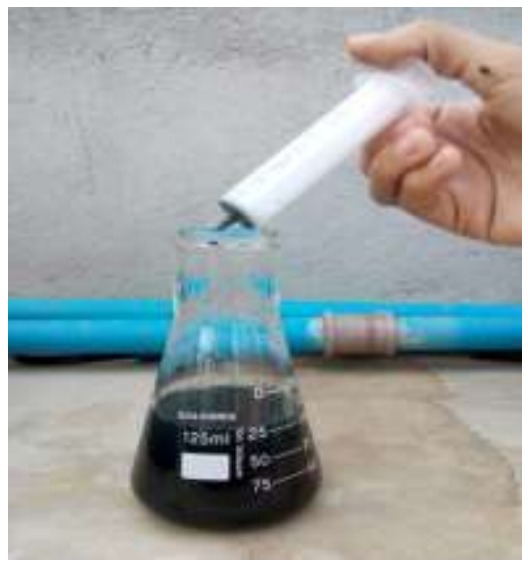

B

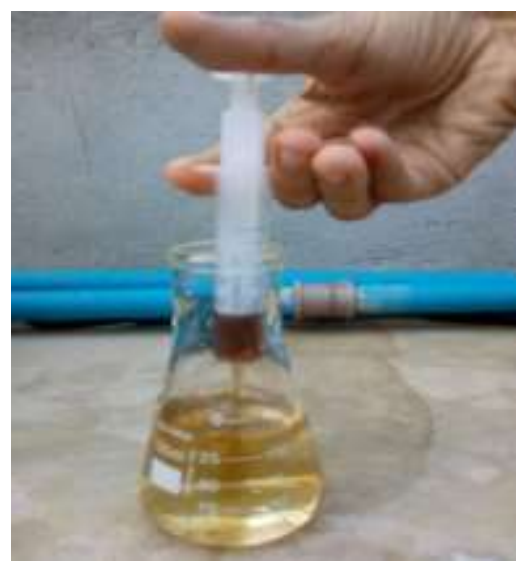

$\mathrm{C}$

Fonte: Autores (2018).

A adubação foi realizada concomitantemente à primeira análise biométrica, os adubos foram aplicados nos substratos, em seguida realizada a irrigação até capacidade de campo, e procedeu-se uma segunda adubação aos 60 DAT.

\section{Tratos culturais}

Devido a certo grau de controle do ambiente em que foi conduzido, não houve incidências de quaisquer formas de pragas que precisassem ser combatidas. Os únicos procedimentos demandados para controle cultural foi o manejo de cada indivíduo, como poda eventual de espécies concorrentes, como gramíneas, herbáceas e urticaceas, bem como irrigação diária, realizada nas primeiras horas do dia, de cada unidade amostral até sua capacidade de campo.

\section{Avalição de crescimento e desenvolvimento}

Para avaliação do crescimento foi realizado a mensuração de altura da parte aérea com auxílio de fita métrica, medindo-se da base correspondendo a distância do nó cotiledonar à extremidade do último par de folhas. Na avaliação do desenvolvimento foi utilizado o paquímetro para medir o diâmetro, também foram observados outros paramentos como número de folhas.

\section{Análise de trocas gasosas}

As análises de trocas gasosas foram realizadas 30 dias após a primeira adubação na terceira folha aberta, completamente expandidas e em bom estado fitossanitário no período entre 08:00 e 12:00 h. Foram determinadas a fotossíntese líquida (A), condutância estomática (gs) e transpiração (E), utilizando um analisador de gás a infravermelho (IRGA) 
transportável, de sistema aberto, modelo LI-6400XT, com a bancada óptica do analisador de amostras abrindo diretamente para a câmara de folha, A cabeça sensora do LI-6400 tem embutidos dois analisadores infravermelhos não dispersivos, completos, de duplos caminhos, ambos medindo concentrações absolutas de CO2 e H2O. O IRGA foi ajustado para trabalhar com fluxo de ar de $400 \mu \mathrm{mol} \mathrm{s}-1$, temperatura da folha fixado em $31^{\circ} \mathrm{C} \pm 1^{\circ} \mathrm{C}$ e concentrações de $\mathrm{CO} 2$ dentro da câmara de medição em torno de $400 \pm 1 \mu \mathrm{mol}$ mol-1, e $1000 \mu \mathrm{mol}$ de densidade de fótons.

\section{Análise laboratorial}

Foram consideradas todas as amostras, resultando em 52 observações, cuja as variáveis aleatórias a elas atribuídas correspondem um valor global de desenvolvimento. Esses valores foram obtidos através da pesagem do material seco e análise foliar. Após a finalização das medições no 120 DAT, os indivíduos foram retirados do vaso e levados para o laboratório de sementes (LabSem), localizado no ICA-UFRA. Todas as amostras foram submetidas a assepsia, em seguida realizou-se a separação das folhas, caule, e raízes em cada planta. Após devidamente separadas, foram colocadas em saco de papel Krafit e conduzidas para os procedimentos e análises.

\section{Área foliar}

Para determinar a área foliar foram destacadas apenas as folhas de todos os indivíduos de cada tratamento, por seguinte as folhas foram colocadas lentamente em um medidor de área LI-3100 da empresa LI-COR (Figura 4 A), conforme a especificação da empresa as amostras foram colocadas entre guias fixas na correia transparente inferior e rolo de pressão ajustável, o qual alisa as folhas onduladas e as alimenta adequadamente entre as correias transparentes, desta forma a amostra passa sob a fonte de luz fluorescente (figura 4 B), a folha projetada é refletida por um sistema de três espelhos para uma câmera de matriz linear dentro do alojamento traseiro. O resultado da área foliar sai em uma tela do próprio equipamento.

Figura 4 - Medidor de área e medição da área foliar de V. merriilli.

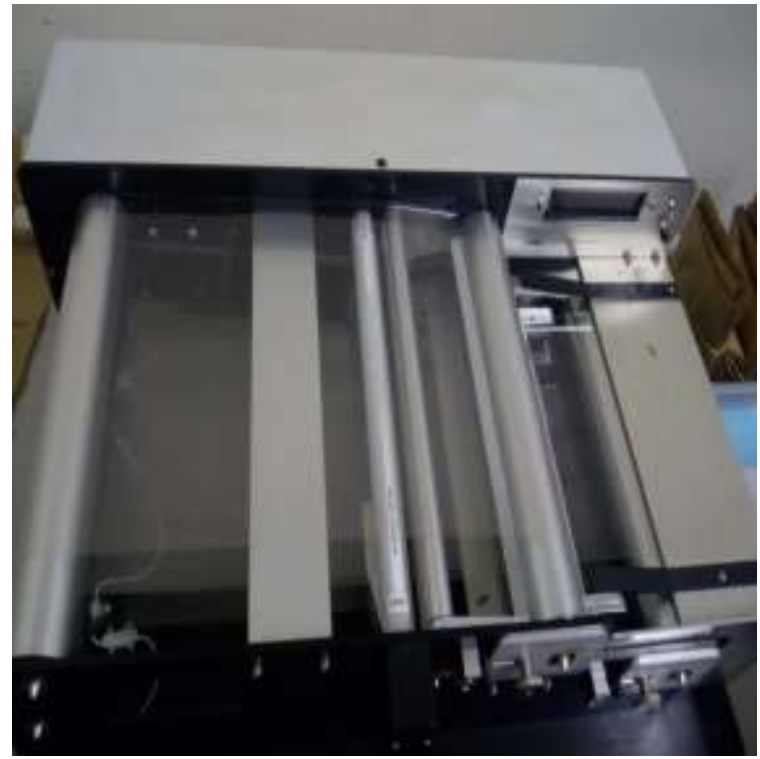

A

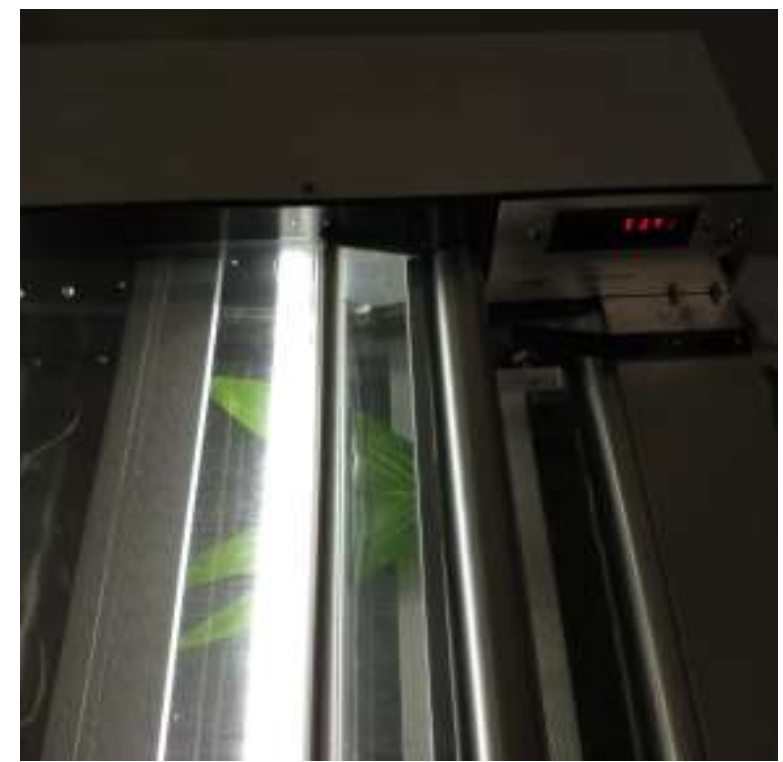

B

Fonte: Autores (2019). 


\section{Pesagem da matéria seca}

Após a separação dos materiais, procedeu-se com a secagem artificial de todas as partes da planta foram alocadas em sacos de papel (Kraft), e submetidas a uma temperatura de $60^{\circ} \mathrm{C}$ durante 72 horas em estufa (Figura 5).

Figura 5 - Secagem das folhas, caules e raízes em estufa.

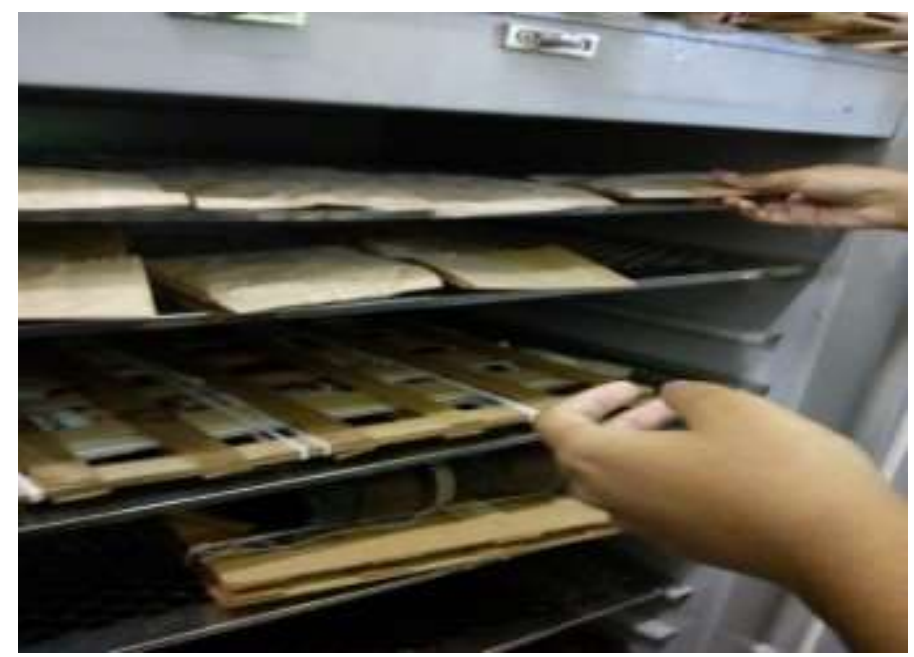

Fonte: Autores (2018).

Os valores referentes à variável que informa a massa seca de cada planta foram medidos com o auxílio dos seguintes instrumentos: Balança analítica digital de 0,0001 de precisão, configurada em gramas; Recipiente de vidro, como tara (Figura $6)$.

Figura 6 - Pesagem da massa seca das folhas (A), caule (B) e raiz (C).

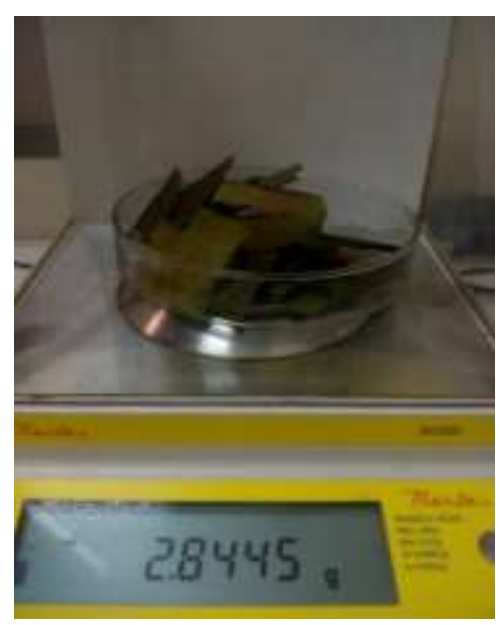

A

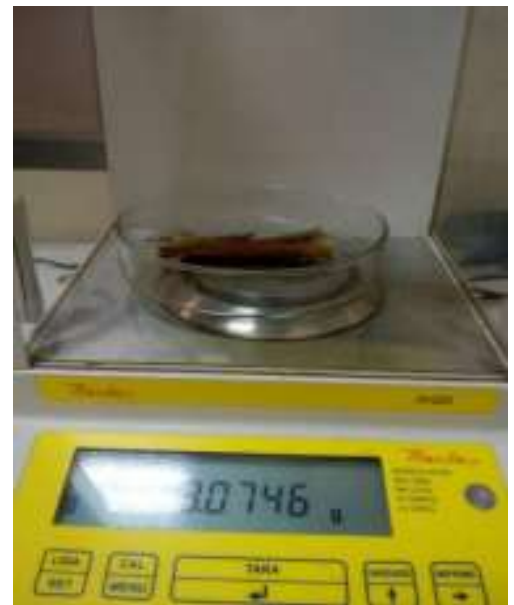

B

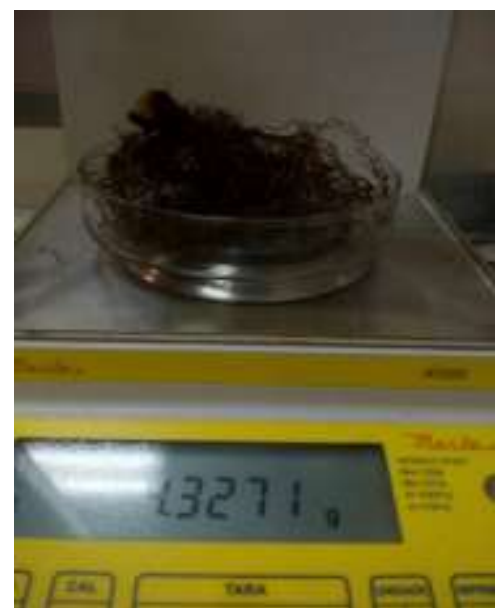

$\mathrm{C}$

Fonte: Autores (2018).

Sendo pesadas separadamente as folhas, caule e raiz de cada indivíduo, tais valores foram registrados e tabulados.

\section{Análise estatística}

Para as variáveis quantitativas relativas ao crescimento e trocas gasosas, bem como para o estudo de dose resposta foram realizadas análises de regressão que expressa uma realidade mais próxima das atividades descritas no âmbito biológico, 
como o desenvolvimento vegetal, utilizando o Software de planilhas eletrônicas Microsoft Excel 2013 como recurso computacional.

\section{Resultados e Discussão}

As mudas apresentaram crescimento lento em todos os tratamentos, ou seja, nas diferentes adubações, contudo esse comportamento é típico da espécie testada. As características de altura da planta (h), diâmetro(D), massa seca (MS), área foliar (AF) e Índices de trocas gasosas, tiveram resultados satisfatórios nas comparações entre doses de cada adubo. Por fim, para o parâmetro número de folhas não houve incrementos significativos para as análises.

\section{Adubação com NPK}

O maior crescimento de altura e diâmetro se deu no intervalo das doses de 10 a 12 gramas, correspondendo aos tratamentos $\mathrm{T}_{3}$ e $\mathrm{T}_{4}$, como observado no Gráfico 1 (Figura 7) de dose resposta, que corresponde à representação gráfica da expressão matemática da relação entre a dose de um princípio ativo e o seu efeito, ou seja, indica o valor mínimo de adubo que é necessário ser aplicado para obter benefício nas plantas. De acordo com as análises, a inflexão negativa da curva mostra o ponto máximo de respostas às doses, inferindo-se que após $12 \mathrm{~g}$ de adubo NPK a planta diminui sua resposta à adubação.

Figura 7 - Comportamento das variáveis altura e diâmetro de planta em função de diferentes doses de NPK nos tratamentos $\mathrm{T}_{1}, \mathrm{~T}_{2}, \mathrm{~T}_{3}$ e $\mathrm{T}_{4}$ de $V$. merrillii.
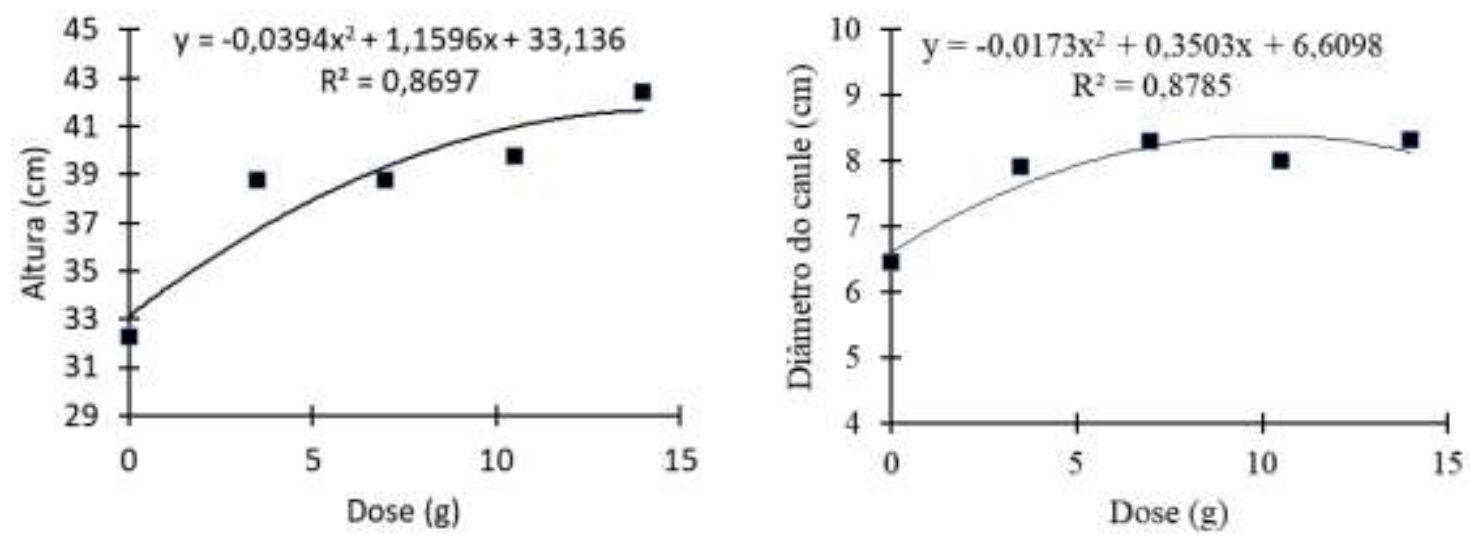

Fonte: Autores (2019).

Através da análise de regressão foi observado que a área foliar dos tratamentos $\mathrm{T}_{1}, \mathrm{~T}_{2}, \mathrm{~T}_{3}$ e $\mathrm{T}_{4}$ Figura 8 (B) obtiveram significância, sendo constatada uma equação de segundo grau, estimando assim uma dose resposta de 9,1806 g, sendo próxima a dose do tratamento T3, o qual apresenta área foliar igual a 529,41. Já para fotossíntese $(A)$, que é demostrado no Figura 8 (A), os dados formam uma equação quadrática crescente, mostrando que mesmo em um área foliar menor em relação ao tratamento 3, a dose da adubação pode estar interferindo na captação da energia luminosa, concluindo-se que a velocidade de produção de energia está aumentando. 
Figura 8 - Analise de dose resposta de fotossíntese $(A)$ e área foliar com adubação NPK em $V$. merrillii.
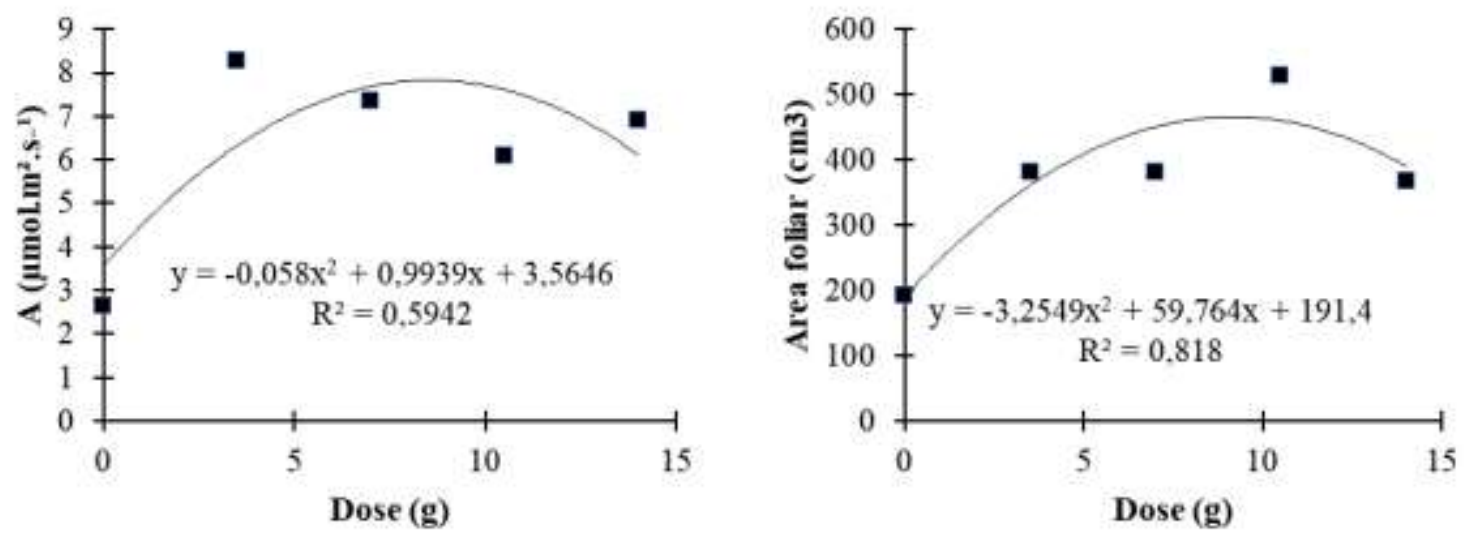

Fonte: Autores (2019).

Para Larcher (2000), a capacidade fotossintética de palmeiras varia, em geral, de 4 a $10 \mu \mathrm{mol} \mathrm{m}^{2} \cdot \mathrm{s}^{-1}$, e em algumas espécies pode atingir valores de até $20 \mu \mathrm{mol} \mathrm{m}{ }^{2} . \mathrm{s}^{-1}$, demonstrando assim que plantas com adubação superior a zero obtiveram resultados satisfatórios (Figura 9).

Figura 9 - Resposta fisiológica do V. merriilli a diferentes doses de adubação NPK.
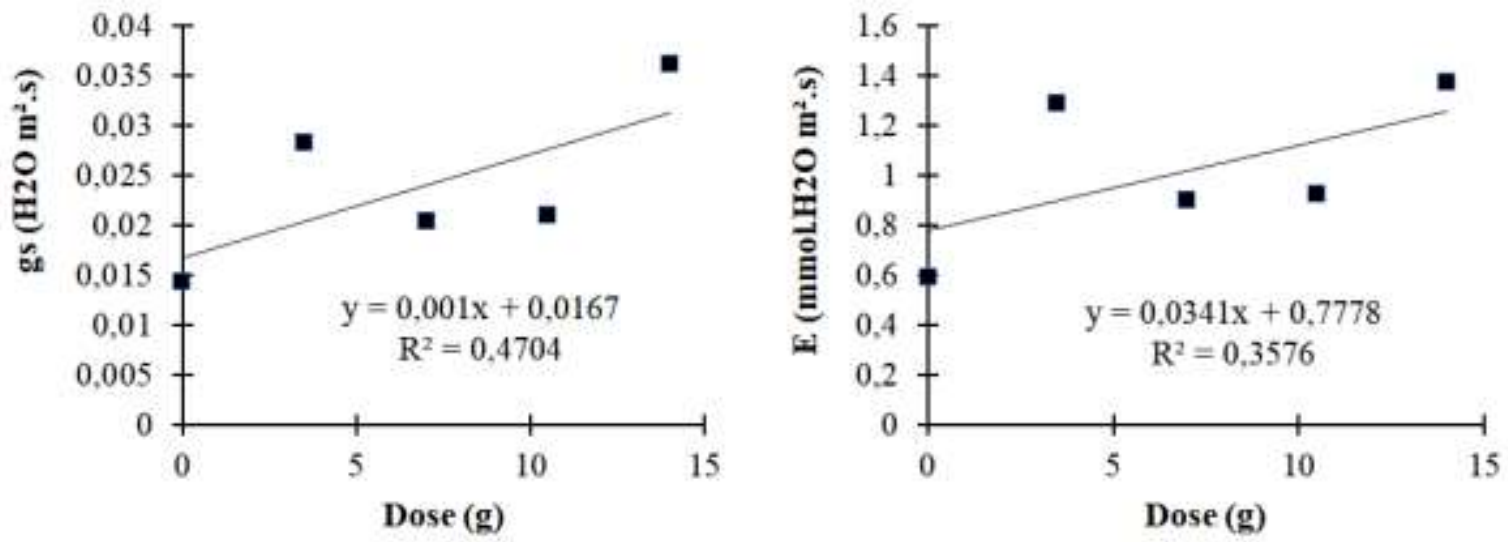

Fonte: Autores (2019).

Segundo Capelin et al., a medida das trocas gasosas é uma ferramenta importante para a verificação do estado fisiológico das plantas. Assim, plantas submetidas a qualquer tipo de estresse apresentam taxa de assimilação de $\mathrm{CO}_{2}(A, \mu$ mol $\left.\mathrm{CO}_{2} \mathrm{~m}^{2} \cdot \mathrm{s}^{-1}\right)$, taxa de transpiração $\left(E, \mathrm{mmol} \mathrm{H}_{2} \mathrm{O} \mathrm{m}{ }^{2} \cdot \mathrm{s}^{-1}\right)$ e condutância estomática (gs, mol $\mathrm{H}_{2} \mathrm{O} \mathrm{m}^{2} \cdot \mathrm{s}^{-1}$ ), entre outras variáveis, diferentes de plantas em condições não estressantes. Então, comparando os resultados obtidos de gs e $A$, ambos apresentam crescimento crescente onde a planta a cada dose de adubação tem maior abertura do estômato e assim possibilita maior entrada e saída de $\mathrm{CO}_{2}$ e água, pode-se inferir que em nenhum dos tratamentos os indivíduos estão em estresse, com exceção da testemunha $\left(\mathrm{T}_{0}\right)$.

Com os resultados da matéria seca (Figura 10), pode-se observar que os resultados de altura e diâmetro coincidem com os de matéria seca, pois em ambos o tratamento 3 se sobressai diante os outros. Nota-se assim para ser mais especifico que a dose resposta para massa da folha, caule e raiz é 13 gramas de adubo NPK. Frisando que após a dose resposta ideal gerado pelo gráfico, teoricamente a planta não utiliza de forma eficiente a adubação. 
Figura 10 - Massa seca da folha (MSF), Massa seca do caule (MSC), Massa seca da raiz (MSR) de V. merrillii adubadas com doses crescentes de NPK.
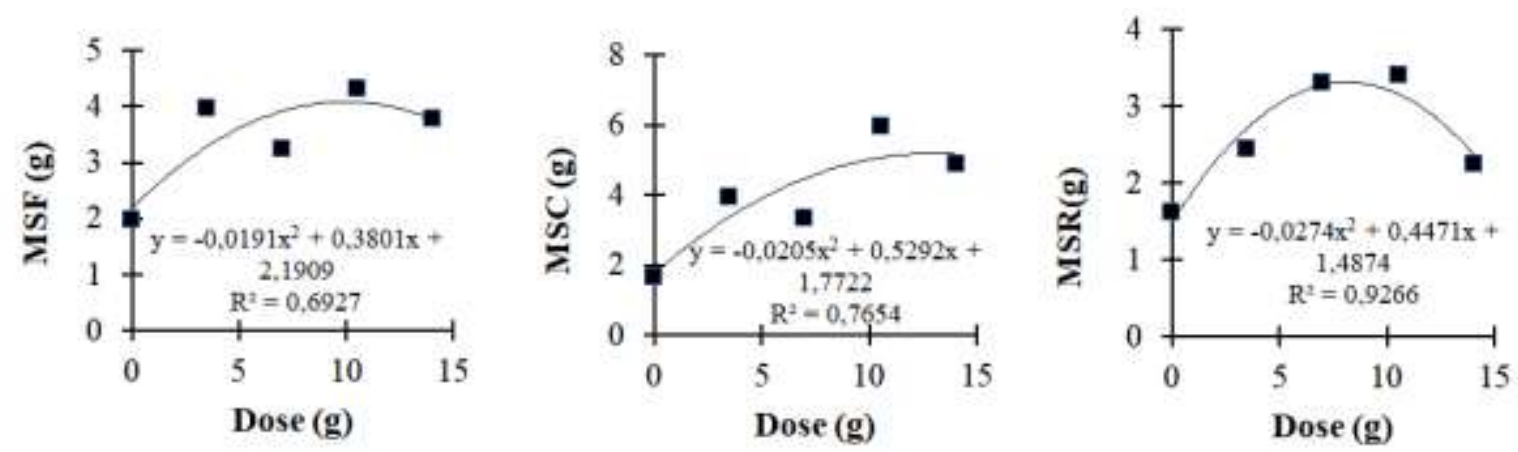

Fonte: Autores (2019).

\section{Fertilizante comercial FORTH palmeiras}

Pôde-se perceber que as doses de fertilizante foliar, obtiveram bons resultados para se inferir qual a quantidade adequada à adubação. De acordo com a Figura 11 (A) a altura do tratamento $\mathrm{T}_{7}$ foi muito superior visualmente, quando comparado aos outros tratamentos. Quando analisado estatisticamente a equação foi obtida uma dose resposta de 13,6205 ml. $\mathrm{L}^{-1}$, estando muito próxima da dose de $15 \mathrm{ml}$. $\mathrm{L}^{-1}$.

Observando as medias de diâmetro dos tratamentos, o tratamento $T_{7}$ também obteve maior resposta a dose aplicada, como visto na Figura 11 (B) sendo fundamental considerar que em uma dose superior a $15 \mathrm{ml} \mathrm{L}^{-1}$ há diminuição do crescimento, e pode-se inferir que a dose ideal para esta característica seja correspondente a do tratamento $\mathrm{T}_{7}$.

Figura 11 - Comportamento das variáveis altura e diâmetro de planta em função de diferentes doses de Fertilizante comercial FORTH palmeiras nos tratamentos $\mathrm{T}_{5}, \mathrm{~T}_{6}, \mathrm{~T}_{7}$ e $\mathrm{T}_{8}$ de Veitchia merrillii.
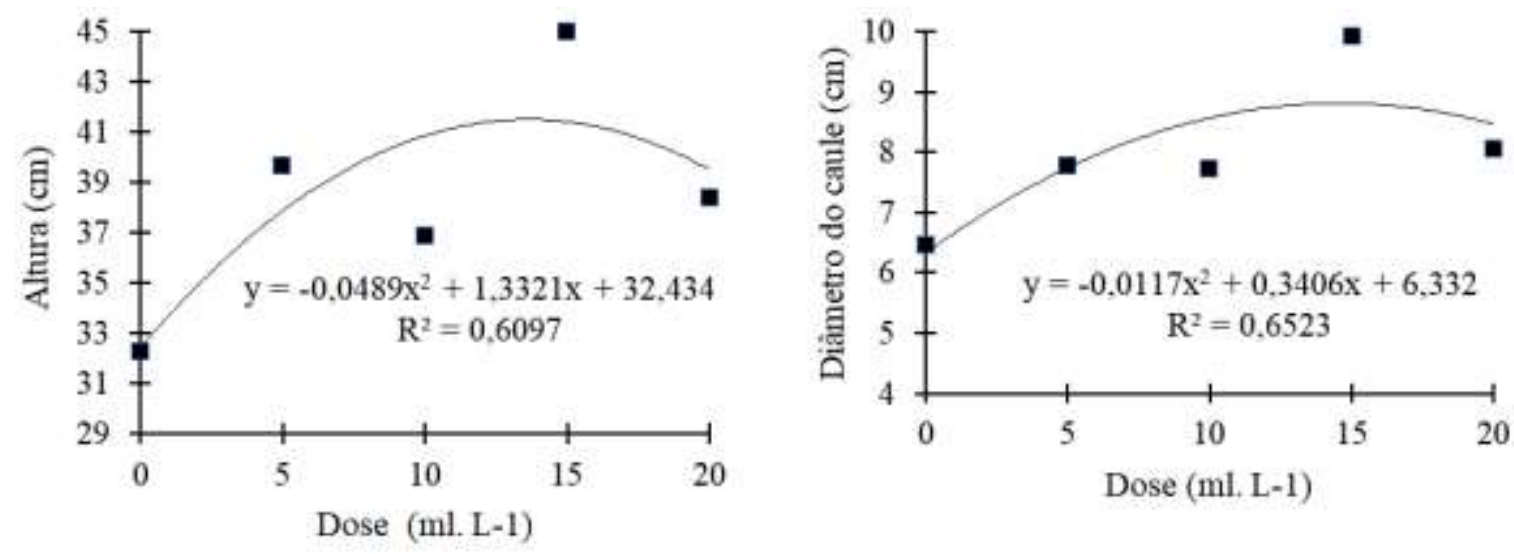

Fonte: Autores (2019).

Foi observado que a fotossíntese está diretamente relacionada à energia necessária para que ocorra o crescimento e desenvolvimento das plantas, pois ao se aumentar a adubação houve um crescimento mais acelerado das mudas de palmeira V. merrillii e consequentemente também houve aumento da fotossíntese, , o que é explicado por Marschner (1999), cujo afirma que a deficiência nutricional das plantas causa decréscimo na taxa de crescimento foliar e portanto o índice de área foliar (IAF), diminuindo assim a fotossíntese e também a duração da área foliar, que representa o tempo no qual as folhas suprem de fotossintatos os drenos. 
Como supracitado palmeiras têm um $A$ de $4 \mu \mathrm{mol} . \mathrm{m}^{2} . \mathrm{s}^{-1}$ à $10 \mu \mathrm{mol} . \mathrm{m}^{2} . \mathrm{s}^{-1}$, desta forma o Figura 12 (A) demonstra o comportamento da fotossíntese e o Figura 12 (B) da área foliar (pode-se notar que em ambas as linhas são quadráticas e crescem até as doses entre $10 \mathrm{ml} . \mathrm{L}^{-1}$ a $15 \mathrm{ml} . \mathrm{L}^{-1}$, quando passam para as doses de $20 \mathrm{ml}$. $\mathrm{L}^{-1}$ ambas diminuem. Desta forma o $\mathrm{T}_{8}$ tem menor área foliar e menor fotossíntese líquida do que $\mathrm{o} \mathrm{T}_{7}$, o qual tem menor dose de adubação.

Guimarães et al. (2002) afirma que há uma grande importância na determinação da área foliar das culturas agrícolas, pois, é explicada pela estreita correlação entre esta e as taxas fotossintéticas e transpiração das plantas, uma vez que reflete a capacidade da planta em interceptar as radiações e efetuar trocas gasosas com o ambiente, constituindo-se assim em importante indicativo da produtividade das culturas.

Figura 12 - Analise de dose resposta de fotossíntese $(A)$ e área foliar com adubação de fertilizante comercial FORTH palmeiras em $V$. merrillii.
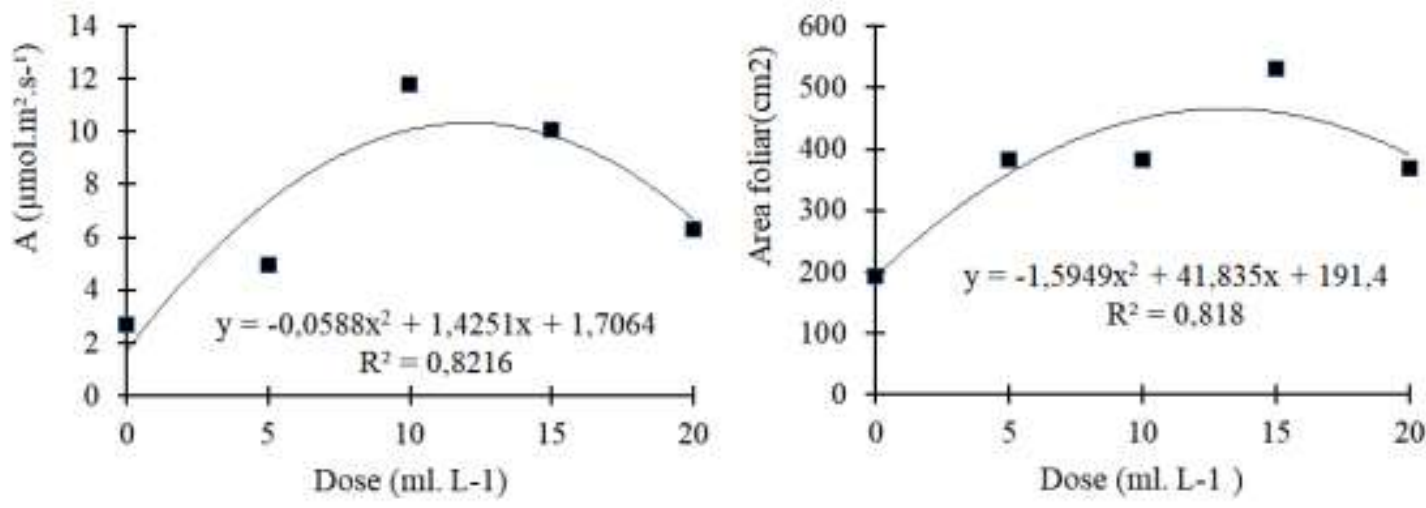

Fonte: Autores (2019).

Sousa (2013), diz que a regulação da condutância estomática ao vapor de água (gs) é um poderoso mecanismo fisiológico que as plantas vasculares possuem para o controle da perda da água, pela transpiração. Por este motivo os valores de gs e E (Figura 13) foram incluídos em gráfico paralelo, pois estes dados tem grande relevância, visto de acordo com o gráfico que quanto maior gs maior será a transpiração. Neste caso a transpiração demonstrado na Figura 13 (B) se comporta de forma diferente da condutância estomática, a qual está representada em uma equação linear crescente, enquanto a fotossíntese é uma equação quadrática que tem seu pico máximo e em seguida diminui. Desta forma para esses parâmetros a dose resposta foi $12,5 \mathrm{ml} . \mathrm{L}^{-1}$.

Figura 13 - Resposta fisiológica do V. merriilli a diferentes doses de adubação de Fertilizante comercial FORTH palmeiras.
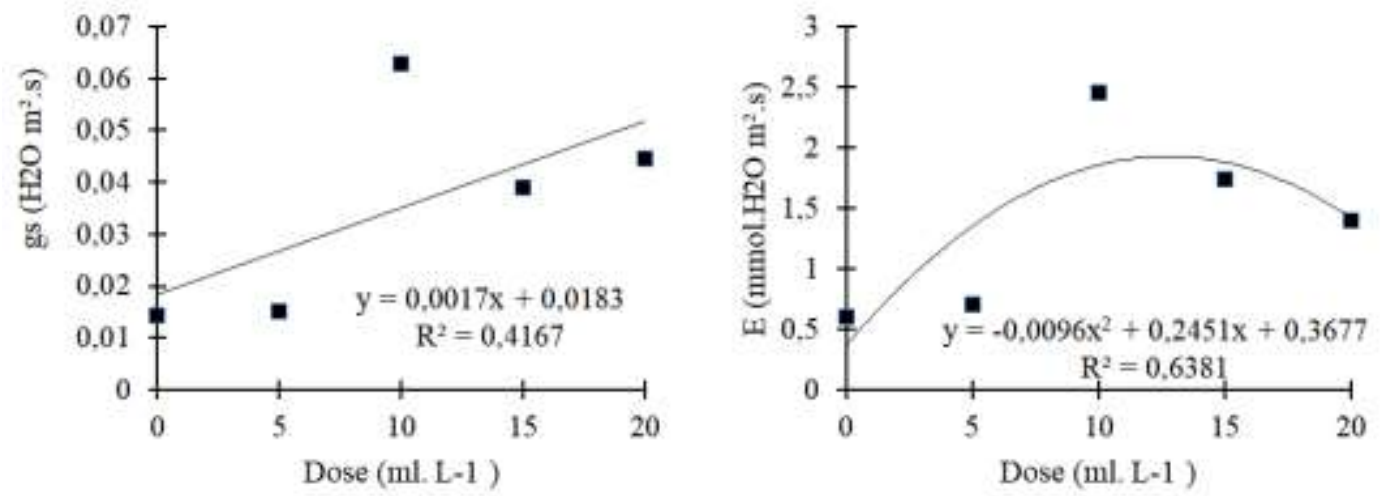

Fonte: Autores (2019). 
A dose resposta média da massa foliar, caulinar e radicular visto na Figura 14 foi de 15,31 ml. $\mathrm{L}^{-1}$, portanto superior a dose resposta do diâmetro e altura. Entre as massas não houve significativas mudanças, podendo ser observado nas linhas traçadas pelo gráfico. Nesta adubação o tratamento destaque foi o $\mathrm{T}_{7} \mathrm{com}$ dosagem de $15 \mathrm{ml} \mathrm{L}^{-1}$ foram indivíduos que não só tinham altura e diâmetro, mas também uma boa massa radicular.

Figura 14 - Massa seca da folha (MSF), Massa seca do caule (MSC), Massa seca da raiz (MSR) de plantas adubadas com doses crescentes de fertilizante FORTH palmeiras $V$. merrillii.

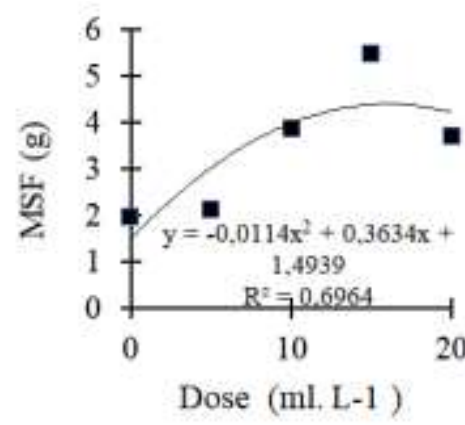

Dose (ml, L-1)

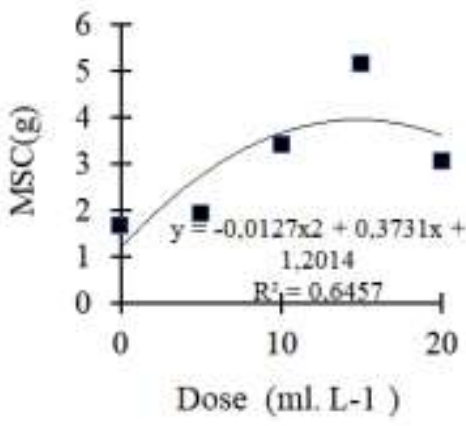

Fonte: Autores (2019).

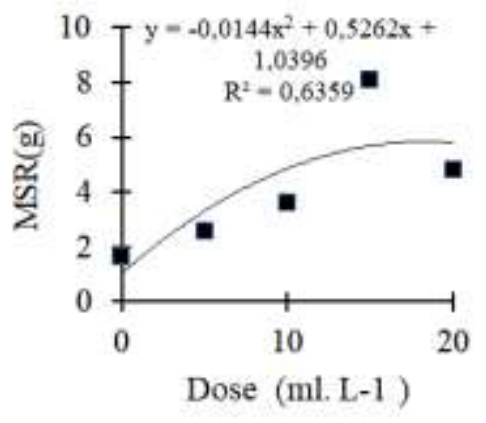

Dose (ml. L-1)

\section{Biofertilizante caseiro orgânico}

Os dados demonstram que os tratamentos $\left(\mathrm{T}_{9}, \mathrm{~T}_{10}, \mathrm{~T}_{11}\right.$ e $\left.\mathrm{T}_{12}\right)$ com biofertilizante obtido através do lixo doméstico tiveram bons resultados, no entanto as doses analisadas no experimento não obtiveram o máximo de crescimento, como demonstra na Figura 15 o qual tanto altura quanto diâmetro forma um gráfico com médias crescentes com pouca ou nenhuma inclinação.

Figura 15 - Comportamento das variáveis altura e diâmetro de planta em função de diferentes doses de Biofertilizante caseiro orgânico nos tratamentos $\mathrm{T}_{9}, \mathrm{~T}_{10}, \mathrm{~T}_{11} \mathrm{e} \mathrm{T}_{12}$ de V. merrillii.

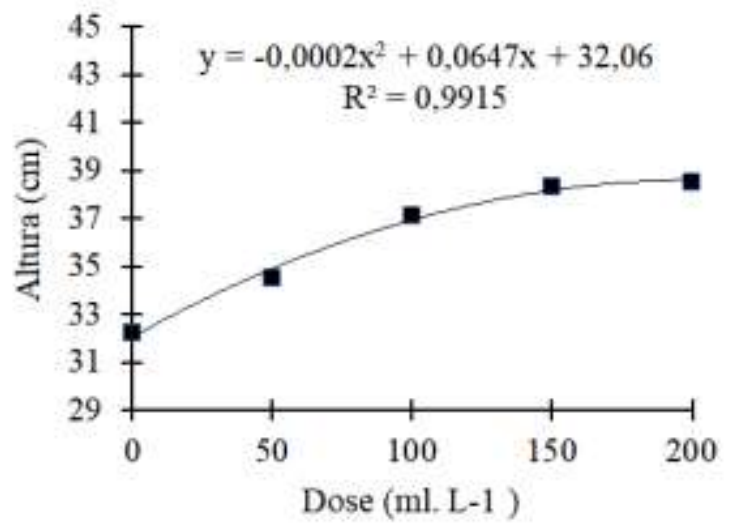

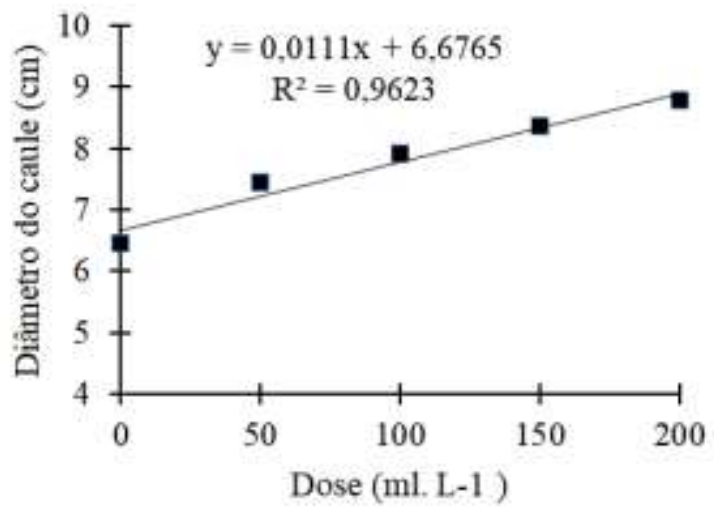

Fonte: Autores (2019).

Desta forma o tratamento $\mathrm{T}_{12}$ tem os dados mais elevados, sendo está considerada a melhor dose para esta adubação, dose de $200 \mathrm{ml} . \mathrm{L}^{-1}$, sendo recomendado uma dose ainda maior para obter resultado mais eficiente.

Resultados semelhantes são demonstrados na Figura 16 em que as doses crescentes de adubação possibilitaram atividade fotossintética também crescente, gerando uma equação linear dos dados obtidos. Relacionando com a Figura 16 (B) 
da área foliar a dose resposta foi similar aos resultados anteriores, sendo este o tratamento $T_{12}$, é importante ressaltar que os dados de área foliar têm crescimento exponencial.

Figura 16 - Analise de dose resposta de fotossíntese $(A)$ e área foliar com adubação Biofertilizante caseiro orgânico em $V$. merrillii.
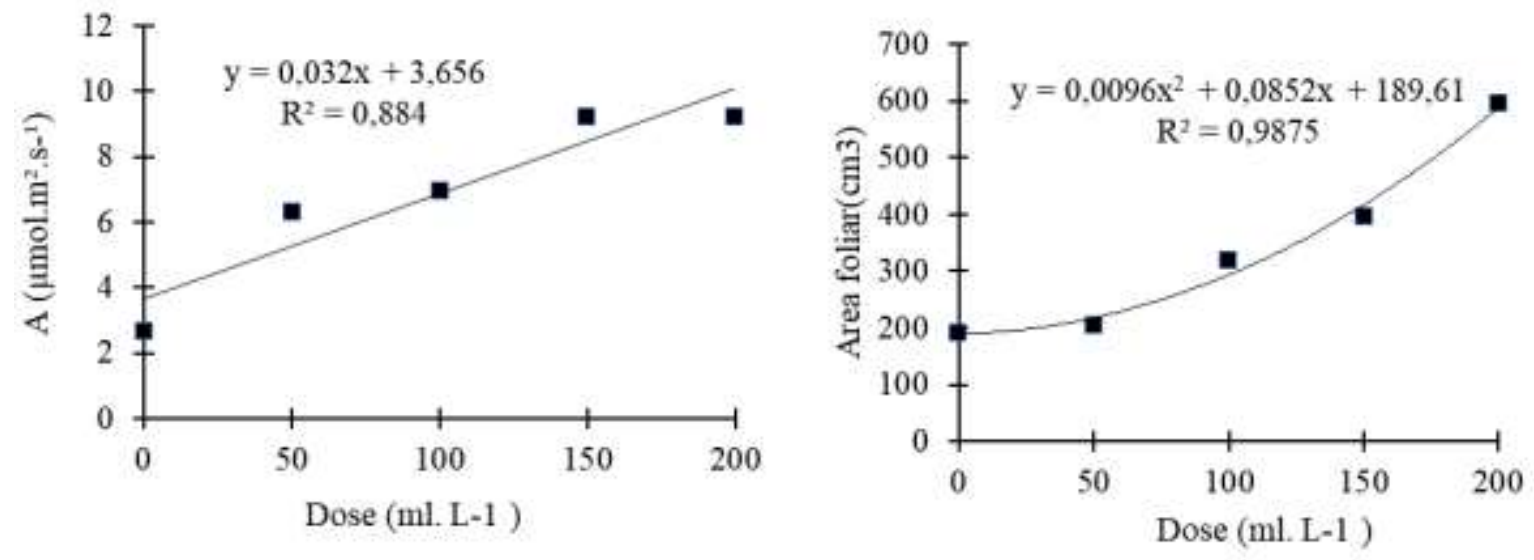

Fonte: Autores (2019).

Em palmeiras, de um modo geral, o fechamento parcial dos estômatos e as altas taxas de fotorrespiração nas horas de maior incidência de raios solares resultam em redução na taxa de assimilação líquida de $\mathrm{CO}_{2}$ ao longo do dia, limitando a fotossíntese (Araus; Hogan, 1994; Franco; Lüttge, 2002 Apud Costa, 2016). A fotossíntese no caso da V. merriilli, o fator mais delimitador foi o estresse causado pela falta de adubação como observado, no entanto ainda tem taxas fotossintéticas altas, principalmente pela sua arquitetura foliar e arranjo espacial das folhas. No entanto quando se observa a condutância estomática e transpiração, nota-se que estes estão em baixas taxas, ocasionados principalmente pela luz solar, mas também pode ter influência da adubação.

Mesmo fotossíntese sendo crescente em equação linear, o gs e $E$ sofrem uma queda dos valores no $\mathrm{T}_{11}$ para o $\mathrm{T}_{12}$, pode-se inferir que o tratamento com dose de $200 \mathrm{ml}$. $\mathrm{L}^{-1}$ pode está gerando algum problema fisiológico que esteja afetando nos movimentos estomáticos para entrada e saída de gases importantes à planta. Na analise do gráfico demonstra que neste caso a

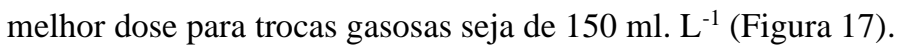

Figura 17 - Resposta fisiológica do V. merrillii a diferentes doses de adubação de Biofertilizante caseiro orgânico.
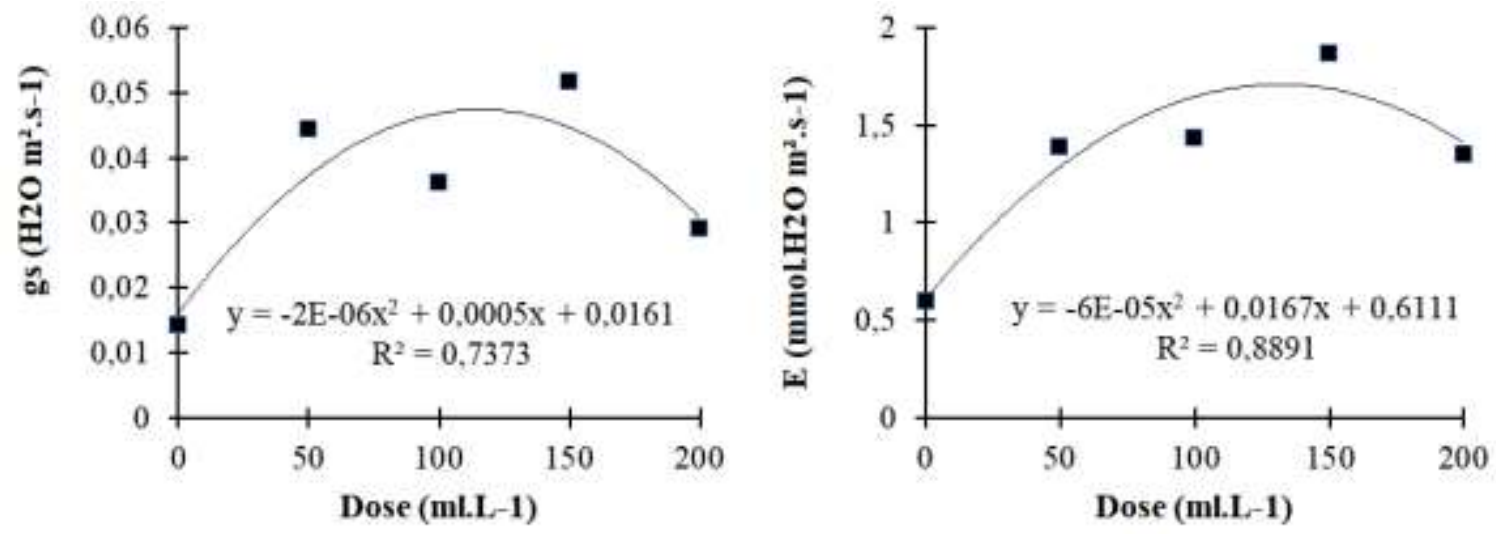

Fonte: Autores (2019). 
Por fim, as massas secas observado na Figura 18, também tem crescimento continuo a medida que se aumenta a dose da adubação, estes dados validam os anteriores demonstrando que nesse experimento não foi possível determinar uma dose ideal do fertilizante. Nota-se que graficamente esta adubação necessita de maiores doses do produto. Portanto, o tratamento 12 foi o que obteve melhores resultados sendo a dose de $200 \mathrm{ml}$. $\mathrm{L}^{-1}$.

Figura 18 - Massa seca da folha (MSF), Massa seca do caule (MSF), Massa seca da raiz (MSR) de plantas de $V$. merrillii adubadas com doses crescentes de biofertilizante caseiro.
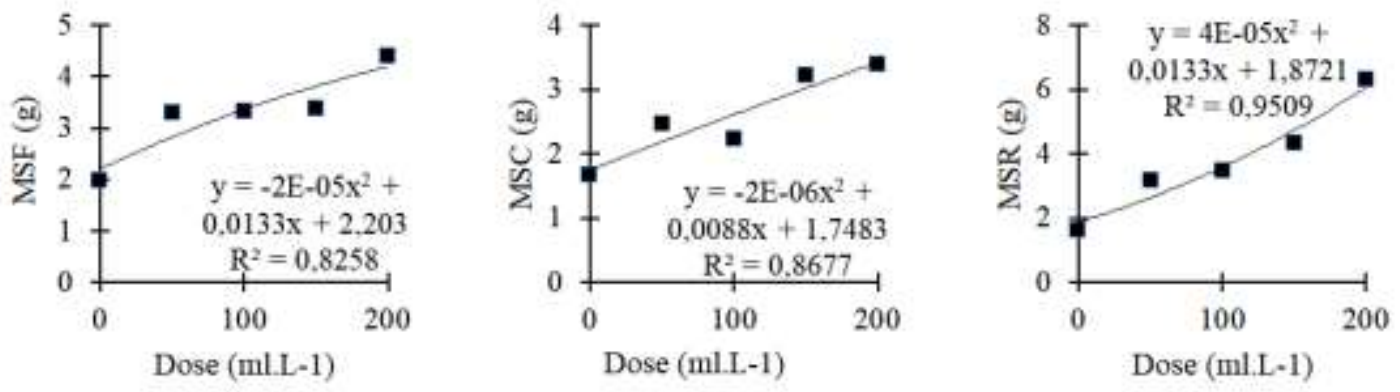

Fonte: Autores (2019).

\section{Análise do potencial paisagístico em comparação dos tratamentos.}

Um importante fator a se considerar é como essas mudas se relacionam com o mercado e por qual valor elas irão ser adquiridas. Desta forma é importante se atentar aos parâmetros visuais que estes indivíduos têm no caso de palmeiras alguns aspectos tem grande relevância na escolha destas para compor um paisagismo, como afirma Pessoa (2002), o qual diz que a qualidade estética da obra paisagista resulta, em primeiro lugar, da utilização correta dos materiais, vivos e inertes.

As proporções de raiz, caule e folha devem ser analisadas com atenção, pois além do aspecto beleza, é importante que os indivíduos tenham resistência e se adaptem no campo. Assim no gráfico 13 demonstra a partição em porcentagem de raiz, caule e folha, pode-se observar que quando há mudança nas doses de adubação às proporções variam, como na dose de 14 g há uma diminuição da porcentagem de folhas e raiz, e um aumento da massa caulinar, este resultado não é interessante para mudas para fins paisagismo tanto pelo aspecto Beleza que se dá pelo número e tamanho das folhas, quanto para adaptação no campo por ter massa radicular baixa (Figura 19).

Figura 19 - Partição de assimilado de matéria seca de folha (MSF), caule (MSC) e raiz (MSR) de V. merrillii em adubação com NPK.

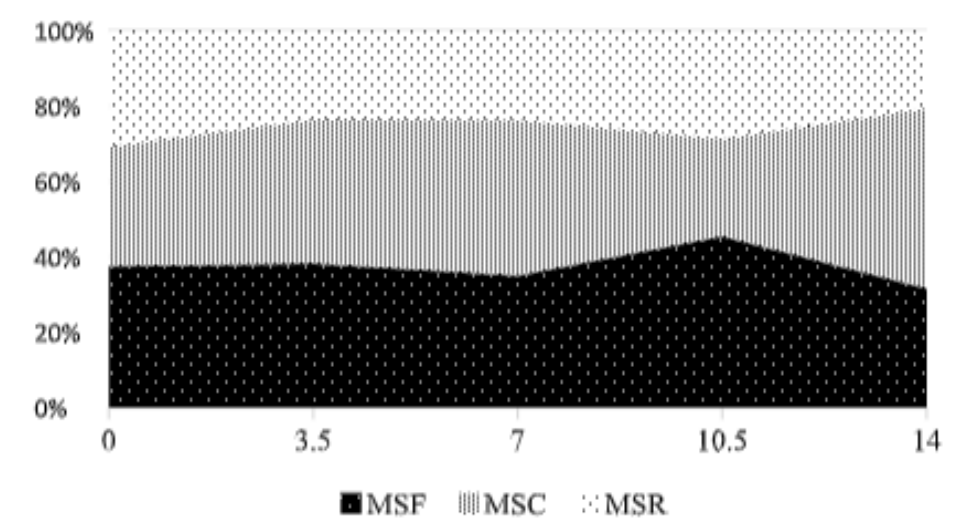

Fonte: Autores (2019). 
Analisando a Figura 19, pode-se inferir que até o $\mathrm{T}_{3}$ o arranjo entre, folha, caule e raiz é o desejado, com $35 \%$ em média de folhas. Resultado diferente foi obtido da adubação de fertilizante comercial para palmeiras (Figura 20), o qual obtém porcentagens maiores de massa radicular chegando até em $27 \%$ no $\mathrm{T}_{7}$, este mesmo tratamento menor porcentagem de folhas em torno de $38 \%$ quando comparado a outras doses deste mesmo tratamento, demonstrando que este tratamento pode ter maior resistência quando for transplantado para campo.

Figura 20 - Partição de assimilado de matéria seca de folha (MSF), caule (MSC) e raiz (MSR) de V. merrillii em adubação com fertilizante comercial.

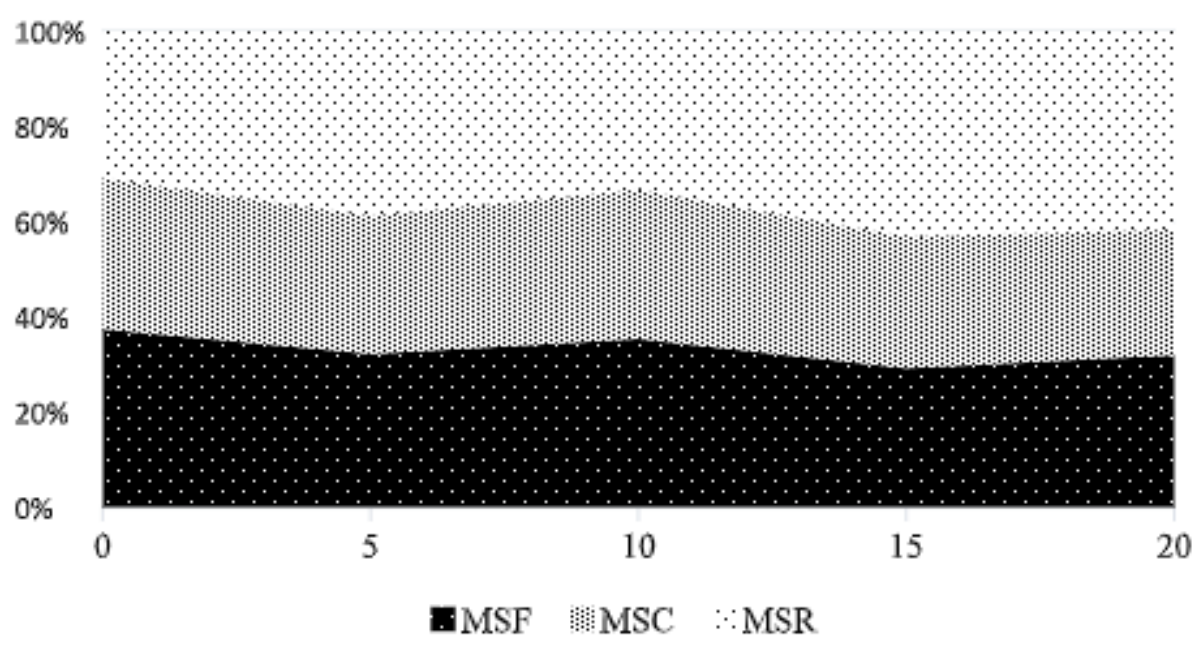

Fonte: Autores (2019).

Percebe-se uma pequena variação na partição (Figura 20) sendo que com o aumento da dose de adubo há um aumento significativo na porcentagem de raízes e diminuindo cerca de $10 \%$ da massa caulinar.

Resultado semelhante se tem na Figura 21 que também com aumento da dose de adubo aumenta a partição radicular, chegando a ter cerca de $35 \%$ de massa de raiz no tratamento 12 , o qual tem a maior dose do adubo. De acordo com as análises de todos os gráficos de partição, pode-se dizer que maior dose de adubação favorece maior crescimento e massa radicular, o que é interessante para a produção de mudas e paisagismo, pois, estas plantas terão maiores reservas quando forem para campo e isto possibilitará continuo crescimento e também aspectos de beleza da planta.

$\mathrm{O}$ aspecto estético de algo se refere às características da beleza e do harmonioso. Nas plantas, essas características podem ser manipuladas através de suas qualidades físicas, que são praticamente a matéria-prima da estética e da beleza (BIONDI apud LEAL, 2006). Portanto, a imagem 7 mostra análise visual das mudas no fim do experimento e as classifica, visto que além de ser belo a planta tem que dar harmonia ao local onde será implantada. 
Figura 21 - Partição de assimilado de matéria seca de folha (MSF), caule (MSC) e raiz (MSR) de V. merrillii em adubação com biofertilizante caseiro.

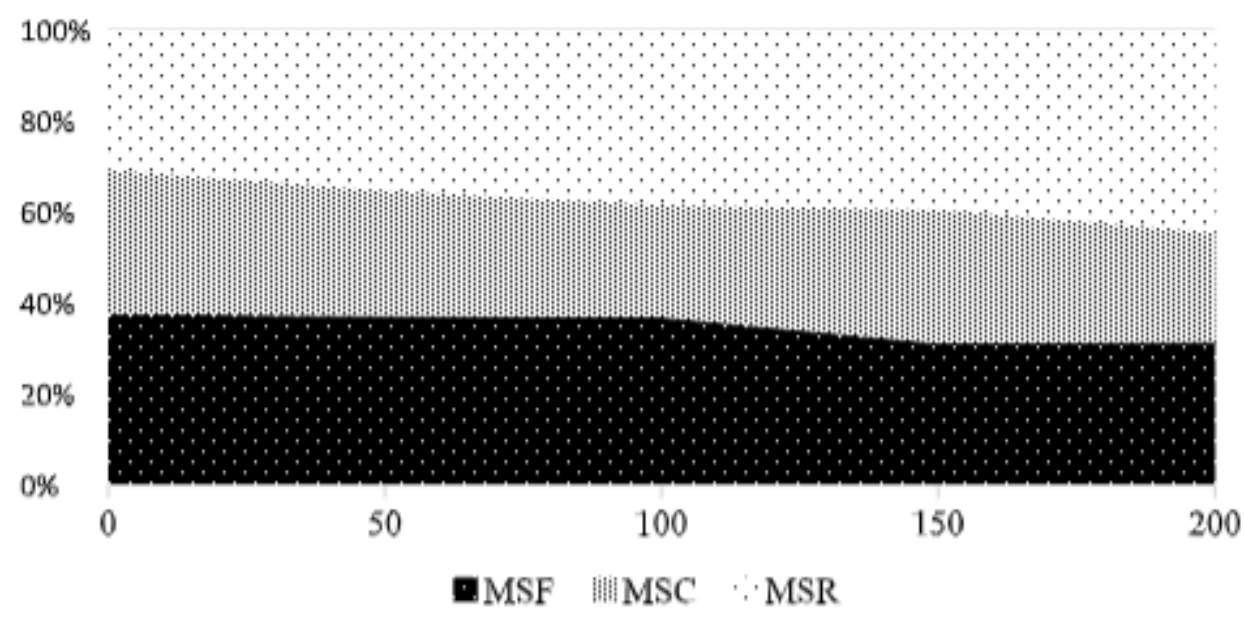

Fonte: Autores (2019).

A imagem complementa os resultados para o potencial paisagístico de cada tratamento, visto que se pode dizer que os indivíduos sem adubação estão inapropriados para o paisagismo, este estado pode ser revertido se estas forem adubadas corretamente. $\mathrm{O}$ inverso se observa nos tratamentos $\mathrm{T}_{3}, \mathrm{~T}_{7}$ e $\mathrm{T}_{12}$ os quais obtém classificação satisfatórias e muito bom.

Os tratamentos como os melhores resultados para cada adubação, no quesito beleza são facilmente absorvidos pelo mercado consumidor. É importante destacar que quando comparados o melhor tratamento de cada adubação o $\mathrm{T}_{7}$ se sobressai diante os demais, sendo este aplicado fertilizante próprio para palmeiras, desta forma este tratamento obtém conceito favorável para ser implantado em jardins e doar sua beleza para o jardim.

Quadro 1 - Análise qualitativa de aspectos de beleza no paisagismo nas diferentes adubações em mudas de V. merrillii.

\begin{tabular}{|llllll|}
\hline \multirow{2}{*}{ ADUBAÇÃO } & TRATAMENTOS & DOSSEL & DIÂMETRO & FOLORAÇÃO & FOLAR \\
\hline Sem adubação & T0 & 1 & 1 & 1 & ALTURA \\
\hline \multirow{4}{*}{ Q } & T1 & 2 & 2 & 1 & 2 \\
& T2 & 2 & 3 & 3 & 2 \\
& T3 & 3 & 4 & 3 & 2 \\
& T4 & 3 & 3 & 2 & 3 \\
FC & T5 & 1 & 2 & 2 & 3 \\
& T6 & 2 & 2 & 1 & 2 \\
& T7 & 4 & 4 & 4 & 3 \\
& T8 & 3 & 2 & 2 & 3 \\
BC & T9 & 2 & 3 & 3 & 3 \\
& T10 & 3 & 3 & 2 & 4 \\
& T11 & 3 & 3 & 3 & 4 \\
\hline
\end{tabular}

*1-Insuficiente; 2- Razoável, 3- Satisfatório; 4- Muito bom

*Q (adubo químico - NPK); FC (fertilizante comercial para palmeiras Forth); BC (biofertilizante caseiro)

Fonte: Autores (2019). 


\section{Conclusão}

A dose que possibilitou melhores resultados de crescimento com adubação de NPK foi o T3, com 10,5 g de dosagem. Já com adubação de fertilizante comercial FORTH, foi o T7 o qual foi aplicado 15 ml.L-1 de adubo. Em ambas adubações depois da dose resposta, o crescimento e desenvolvimento diminuiu com o aumento da dose de adubação.

Não se obteve dose resposta para a adubação com biofertilizante caseiro, pois a maior dose possibilitou o maior resultado dos dados, ou seja, é necessário realizar mais pesquisas e trabalhos sobre essa fonte de adubação.

As trocas gasosas em todos os tratamentos, com exceção da testemunha, tiveram resultados significativos, demostrando que possivelmente está espécie seja uma planta $\mathrm{C} 4$, com altos valores de fotossíntese, e baixa transpiração, estando estas relacionadas com a dose adubada, assim como também a água e temperatura que está sendo inserida.

Quanto ao potencial paisagístico dos indivíduos analisados, o T7 (fertilizante de palmeiras FORTH) teve as melhores características de beleza e adaptabilidade, por além de apresentar crescimento e desenvolvimento superior aos demais tratamentos, aparentava estar mais saudável e esteticamente mais belo.

\section{Referências}

Alves, M. R. P. (1987). Palmeiras. Características botânicas e evolução. Fundação Cargill, 129p.

Anjos, J. L. \& Andrade, L. N. T. (2008). Produção de húmus de minhoca com resíduos orgânicos domiciliares. EMBRAPA. 10p.

Barbosa, Z., Soares, I. \& Crisóstomo, L. A. (2003). Crescimento e absorção de nutrientes por mudas de gravioleira. Revista Brasileira de Fruticultura, Jaboticabal, 25(3), 519-522.

Benincasa, M. M. P. (2003). Analise de crescimento de plantas: noções básicas. (2a ed.).

Bidone, F. R. A. \& Povinelli, J. (1999). Conceitos Básicos de Resíduos Sólidos. p.120.

Biondi, D. (1990). Paisagismo. Universidade Federal de Pernambuco, 184 p.

Bovi, M. L. A., Godoy Jr, G., \& Spiering, S. H. (2002). Respostas de crescimento da pupunheira à adubação NPK. Scientia Agricola, 59(1), $161-166$.

Bredemeier, C. \& Mundstock, C.M. (2000). Regulação da absorção e assimilação do nitrogênio nas plantas. Ciência Rural, 30:365-372.

Capelin, D., Daneluzzi, G. S., De Oliveira, R. F., Bressan, D. F., Corrêa, C. V., \& Costa, T. A. (1983). Utilização do irga-analisador de gases por infravermelho para avaliação de trocas gasosas em plantas: check list de preparação Corley, R. H. V., Photosynthesis and age of oil palm leaves. Photosynthetica.

Costa, S. J. D. (2016). Avaliação biométrica e fisiológica na fase vegetativa do Dendezeiro (Elaeis guineensis Jacq.) em região de cerrado do Tocantins.Tese.

Demétrio, V. A., Chaddad, J., Lima, A. M. L. P.\& Chaddad Junior, J.(2000). Composição paisagística em parques e jardins. Piracicaba, SP: ESALQ. 103p.

Ennahli S., Earl, H. J. (2005). Physiological Limitations to Photossynthetic Carbon Assimilation in Cotton under Water Stress. Crop Science.

Fernandes, P. V. G.(2015). Os desafios do mercado de flores e plantas ornamentais no Brasil. Universidade Federal do Paraná.

Ferreira, E. (2004). Palmeira Brasileiras e Exóticas Cultivadas. Instituto Plantarum de Estudos da Flora. Nova Odessa. 416p.

Furlani, A. M. C.\& Castro, C. E. F. (2001). Plantas ornamentais e flores. In: Ferreira et al. Micronutrientes e elementos tóxicos na agricultura. Jaboticabal: CNPq.

Guimarães, D. P., Sans, L. M. A. \& Moraes, A. V. C. (2002). Estimativa da Área Foliar de Cultivares de Milho. Florianópolis, SC. https://www.embrapa.br/busca-de-publicacoes/-/publicacao/485710/estimativa-da-area-foliar-de-cultivares-de-milho.

Harper, J.E. (1994). Nitrogen metabolism. In: Boote, K.J., Bennett, J.M., Sinclair, T.R. \& Paulsen, G.M., eds. Physiology and determination of crop yield. Madison, ASA/CSSA/SSSA. p. 285-302.

Hartley, C.W.S. (1997). The oil palm (Elaeis guineenses Jacq.) (2a ed.), Tropical Agriculture Series.

Hopkins, W. G. \& Norman P. A. H. (2008). Introduction to Plant Physiology. (2a ed.), John Willy.

Junqueira, A.\& Peetz, M. (2008). Exportações de flores e plantas ornamentais superam US\$ 35 milhões em 2007 : recorde e novos desafios para o Brasil análise conjuntural da evolução das exportações de flores e plantas ornamentais do Brasil no período de janeiro a dezembro de 2007 . São Paulo.

Koslowski, T. \& Pallardy, S. G. (1997). Photosynthesis. IN: Physiology of Woody Plants. (2a ed.).

Larcher, W. (2000). A planta sobre estresse. Ecologia Vegetal. 
Larcher, W. (2000). Ecofisiologia Vegetal. Trad. Carlos Henrique B. A. Prado. Rima. 531p.

Leal, L., Biondi, D. (2006). Potencial ornamental de espécies nativas. Revista Científica Eletrônica de Engenharia Florestal, 8, 1-16.

Lira, B. J. D. M. (2018). Plano de reaproveitamento dos resíduos verdes por compostagem-UFRN campus central, Bachelor's thesis, Universidade Federal do Rio Grande do Norte.

Lorenzi, H. (2008). Árvores brasileiras: manual de identificação e cultivo de plantas arbóreas nativas do Brasil. 5.ed. Instituto Plantarum de Estudos da Flora. v. $1.384 \mathrm{p}$

Lorenzi, H., Souza, H. M., Medeiros-Costa, J. T., Cerqueira, L. S. C., Lorenzi, H, Noblick, L., Kahn, F. \& Ferreira, E. (2010). Flora Brasileira. Arecaceae (Palmeiras). Nova Odessa, SP: Instituto Plantarum de Estudos da Flora Ltda, 384p.

Luna, J. M. E. A., Hernández, D. F., Díaz, J. M. B. \& García, F. E. (2014). Seed germination and pruning effect in the posttransplant establishment of Palma Herpes [Veitchia merrillii (Becc.), H. E. Moore, Arecaceae]. Cultivos Tropicales, 35(4), 75-8.

Luz, P. B. (2008). Germinação e aspectos morfológicos de sementes de Archontophoenix cunninghamii h. Wendl. e drude (Arecaceae). Tese (Doutorado em Agronomia) - Faculdade de Ciências Agrárias e Veterinárias, Universidade Estadual Paulista, Jaboticabal, 63f.

Malavolta, E. (1980). Elementos de nutrição mineral de plantas. Ceres. 251p.

Malavolta, E. (1976). Manual de química agrícola. Agronômica Ceres. 528 p.

Marschner, H. (1999). Yild and the source-sink relationships, Mineral nutrition of higher plantas. (2a ed.),

Oliveira, A. M. G., Aquino, A. M. \& Castro, M. T. N. (2005). Compostagem caseira de lixo orgânico doméstico. EMBRAPA.

Ornelass, A. C. \& Mesquita, G. M. (2017). Uso do biodigestor caseiro destinado ao tratamento de resíduos orgânicos domésticos. Revista eletrônica de educação da faculdade Araguaia, 12: 61-69.

Paiva, A. S., Fernandes, E. J., Rodrigues, T. J. D., \& Turco, J. E. P. (2005). Condutância estomática em folhas de feijoeiro submetido a diferentes regimes de irrigação. Engenharia Agrícola, 25(1), 161-169. https://doi.org/10.1590/S0100-69162005000100018

Pessoa, F. S. \& Telles, G. R. (2002). Esboço Biográfico. Costa do Castelo Filmes.

Pires, A. S. (2006). Perda de diversidade de palmeiras em fragmentos de Mata Atlântica: padrões e processos. Tese de Doutorado, Instituto de Biociências da Universidade Estadual Paulista, Rio Claro, 108p.

Prance, G. T., Balee, W., Boom, M. B. \& Carneiro, R. L. (1987). Quantitative Ethenobotany and Case for Conservation in Amazon. Conservation Biology. $1(4), 296-310$.

Rodrigues, M. R. L., Amblard, P., Silva, E. B., Macêdo, J. L. V., Cunha, R. N. V. \& Tavares, A. M. (2002). Avaliação do estado nutricional do dendezeiro: análise foliar. Embrapa, Manaus, AM Dezembro.

Romano, H. M. (2015). Viabilidade econômica da compostagem na CEASA/SJ. 2015. 81 f. Dissertação (Mestrado) - Programa de Pós-graduação em Agroecossistemas, Centro de Ciências Agrárias, Universidade Federal de Santa Catarina, Florianópolis.

Schalch, V., Massukado, L. M \& Bianco, C. I. (2015). Compostagem. In: Nunes, R. R., Rezende, M. O. de O. Recurso do Solo: Propriedades e Usos. São Carlos: Cubo, Cap. 19. p. 633-659.

Soares, A. N. R., Rocha Júnior, V. F., Vitória, M. F. \& Silva, A. V. C. (2016). Germinação de sementes de nim em função da maturidade fisiológica e do substrato. Nucleus, 13(1), 215-222.

Sodré, J. B. (2005). Morfologia Das Palmeiras Como Meio De Identificação E Uso Paisagístico. 65p.

Souza, C. D. (2008). Comportamento ecofisiológico de espécies arbóreas nativas do Cerrado e exóticas. Tese. Goiânia.

Souza, L. A. (2013). Comportamento ecofisiológico de Attalea microcarpa Spruce e Attalea attaleoides Mart. ao longo do gradiente topográfico (platô, vertente e baixio), em uma floresta de terra firme ao norte de Manaus. INPA.

Tomlinson, P. B. (1990). The structural biology of palms. Clarendon Press. 463 p.

Torres, J. L. R. \& Pereira, M. G. (2008). Dinâmica do potássio nos resíduos vegetais de plantas de cobertura no Cerrado. R. Bras. Ci. Solo, 32:1609-1618.

Trindade, S. (2010). A palmeira. Jardinagem e Paisagismo.

Tucci, M. L. S. (2004). Variação Estacional do Crescimento de Trocas Gasosas em Pupunheira (Bactris gasiapaes Kunth).

Ubalua, A. O. (2007). Cassava wastes: treatment options and value addition alternatives. African Journal of Biotechnology, 6(18), 2065-2073.

Witt, H. H. (1997). Root growth of trees as influenced by physical and chemical soilfactors. Acta Horticulturae, (450), 205-214.

Wykoff, D. D., Davies, J. P., Melis, A. \& Grossman, A. R. (1998). The regulation of photosynthetic electron transport nutrient deprivation in Chlamydomanas reinhardtii. Plant Physiology, 117: 129-139. 